\title{
The Effects of Licorice Root Powder (Glycyrrhriza glabra) on Performance, Serum Parameters, Egg Yolk Cholesterol and Antioxidant Capacity of Laying Japanese Quail
}

\author{
Sibel Canoğulları Doğan ${ }^{\text {* }}$, Zeynep Erdoğan², Ahmet Şekeroğlu', Mikail Baylan², \\ Altuğ Küçükgül ${ }^{4}$ \\ ${ }^{I}$ Department of Animal Production and Technologies, Niğde Ömer Halisdemir University, Faculty of Agricultural Sciences and \\ Technologies, 51240 Niğde, Turkey \\ ${ }^{2}$ Food Processing Department, Arda Vocational School, Trakya University, 22030 Edirne, Turkey \\ ${ }^{3}$ Department of Animal Science, Agriculture Faculty, Çukurova University, 01380 Adana, Turkey \\ ${ }^{4}$ Faculty of Veterinary Medicine, Mustafa Kemal University, 31060 Hatay, Turkey
}

\section{A R T I C L E IN F O}

\section{Research Article}

Received 17 July 2018

Accepted 04 September 2018

Keywords:

Antioxidant capacity

Cholesterol

Licorice root

Performance

Quails

*Corresponding Author:

E-mail: sibelcanogullari@gmail.com

\begin{abstract}
A B S T R A C T
This study was conducted with the objectives to determine the effects of licorice root powder (Glycyrrhriza glabra) on performance, serum parameters, egg yolk cholesterol and antioxidant capacity in laying Japanese quail. Two hundred and forty 10-wk-old Japanese quails were randomly assigned to four dietary groups, each one four times replicated with fifteen quails per dietary groups. Control group fed the basal diet; other groups were fed basal diet supplemented with $0,0.5,1.0$ and $1.5 \%$ licorice root powder. There were no significant differences in terms of final live weight, feed intake, feed conversion ratio, egg weight, serum cholesterol, triglyceride and High-Density Lipoprotein (HDL) concentration between treatment groups. Egg production was higher in control group and $0.5 \%$ licorice root powder supplemented groups. $1.0 \%$ licorice root powder supplemented group had lower egg production rate. Licorice root powder supplementation decreased Low Density Lipoprotein (LDL) concentration and increased glucose concentration significantly. Licorice root powder supplementation increased total antioxidant status (TAS) and reduced total oxidant status (TOS) and oxidative stress index (OSI). It was concluded from this study that supplementation of licorice root powder at the level of $0.5,1.0$ and $1.5 \%$ to the feed of laying quails had no adverse effects on performance. Licorice root powder supplementation can be used to reduce cholesterol level and increase antioxidant status in quails.
\end{abstract}

DOI: https://doi.org/10.24925/turjaf.v6i9.1290-1296.2124

\section{Introduction}

Many of the medicinal and aromatic plants present in the nature are natural and reliable, they have been widely used for medical purposes and spices for centuries due to their various pharmacological effects. These plants have various functional properties due to the bioactive components they contain (Kohlert et al., 2000). When plants and extracts are consumed by humans and animals, they are regarded as safe additives that are safe from chemical point of view. The use of medicinal and aromatic plants in animal nutrition has increased, in order to replace the use of antibiotics especially after the ban of antibiotic feed additives within the European Union countries in 2006 (Franz et al., 2010).

Licorice root (Glycyrrhiza glabra) is among the oldest and most widely known medicinal plants in the world. Glycyrrhiza glabra is a perennial herb, native to central and South-Western Asia, as well as to the Mediterranean region and cultivated in temperate and sub-tropical regions of the world, including Europe and Asia. The root, dried and processed, is called licorice and has a characteristic odor and sweet taste (Fiore et al., 2008).

Licorice root, Glycyrrhiza genus, belongs to the Fabaceae family, and there are about 30 species spread all over the world (Shibata, 2000). The roots of the plant are widely used in medicinal and industrial environments in many countries. Despite the fact that licorice plant has been used for many years in traditional herbal medicine, its composition and pharmacologically active compounds have been revealed through modern analytical techniques and scientific research conducted over the last 25-30 years (Asl and Hosseinzadeh, 2008). The majority of these bioactive compounds are triterpene saponins (4-20\%) and various types of phenolic compounds (Fiore et al., 2008; Tan et al., 2010). 
Glycyrrhizin and flavonoids, such as liquiritin, isoliquiritin and their aglycones, have been reported as the major constituents of licorice and they are perceived as the active principles responsible for its pharmacological efficacy (Zhang and Ye, 2009). Glabridin which is the main isoflavonoid compounds of the plant has been reported to have potent antioxidant activity (Shibata, 2000).

The effects of glycyrrhizin (glycyrrhizin) and glycyrrhetic (glycyrrhetic) acid as the main compounds of triterpene saponins have been demonstrated as antioxidant (Ju 1989; Vaya et al., 1997; Doğan, 2004), antiinflammatory (Yokota et al., 1998), anti-viral (Fiore et al., 2008), anti-allergic, anticarcinogenic and immunomodulatory with the results of clinical and experimental studies (Shibata, 2000; Asl and Hosseinzadeh, 2008). Other important effects of glycyrrhizin and glycyrrhetic acid have been reported to have cardioprotective, hepatoprotective and plasma lipidlowering effects (Fuhrman et al., 2002, Nakagawa et al.,2004, Visavadiya and Narasimhacharya, 2006).

Vaya et al. (1997) investigated the effect of antioxidant substances of licorice root on the LDL oxidation. They have identified 7 isoflavan substances in the root. (Hispaglabridine, Glabridin, methylglabridine isoprenylchalcone derivatives, Isoliquiritigenin, isoflavone and Formononetin). These antioxidants have been shown to be highly effective against LDL oxidation. Nitalikar et al. (2010) reported that licorice root extract have antimicrobial effects on gram-positive (Bacillus subtilis and Stapphylococcus aureus) and gram-negative bacteria (Escherichia coli and Pseudomonas aeruginosa). Sen et al. (2011) reported that glycyrrhizin which is one of the key components of the licorice root bring oxidative stress parameters such as Superoxide dismutase (SOD), catalase and malondialdehyde (MDA) to normal levels in diabetic mice. There is a very limited number of studies have been conducted on the use of licorice root powder or extract as supplement in laying hens or quails diet.

For this purpose, present study were investigated the effects of the licorice root powder (Glycyrrhriza glabra) on performance, serum parameters, egg yolk cholesterol and antioxidant capacity in laying Japanese quail.

\section{Material and Method}

\section{Bird and Diet}

The experimental procedures for this study were reviewed and approved by the Local Animal Care and Use Committee of Çukurova University (29.12.2014/8). Two hundred and forty 10-wk-old laying Japanese quails of similar live weight $(370.48 \pm 2.156 \mathrm{~g})$ were randomly divided into four dietary treatments. Each treatment was consisted of 4 replicates with 15 birds in each. Quails were weight individually at the beginning and at the end of the experiment. Birds were transferred to wire cages (15 birds each) which were $50 \times 50 \times 20 \mathrm{~cm}$. Each cage was equipped with a trough-type feeder and a nipple drinker.

Quails were fed a basal diet as a control group and other groups were fed basal diet supplemented with $0,0.5$, 1.0 and $1.5 \%$ licorice root powder. In order to add the licorice root powder to the basal diet, a small amount of diet was first taken and mixed with a certain amount of licorice root powder. This mixture was then added to the diet and mixed until the diet became homogenous.

The basal diet was formulated to meet the nutrient requirements of laying quails according to NRC (1994) (Table 1) Licorice root was obtained from Hatay province which is situated in southern Turkey, on the eastern Mediterranean coast. After the licorice root was powdered, it was given to the quails.

Chemical composition of licorice root was determined as $9.15 \%$ protein, $0.53 \%$ fat, $6.80 \%$ moisture, $7.70 \%$ ash, $24.48 \%$ fiber, $47.11 \%$ Carbohydrate, $1720 \mathrm{mg} / 100 \mathrm{~g} \mathrm{Ca}$, 78 mg/100g P, 185.80 ppm Na, 7276 ppm K, 1224 ppm Fe (Badr et al., 2103).

Production performance such as feed intake, egg number, egg weight and bird mortality of each replicate was recorded daily. Feed conversion ratio (FCR) was calculated according to following formula:

$$
\mathrm{FCR}=\frac{\text { Feed consumption }(\mathrm{g} / \text { week })}{\text { Egg weight }(\mathrm{g} / \text { week })}
$$

Egg mass was calculated by multiplying egg weight by egg production. During the 8 -week experimental period $16 \mathrm{~h}$ light $8 \mathrm{~h}$ dark was applied and feed and water were given for ad-libitum consumption.

\section{Egg Yolk Cholesterol}

In order to determine egg yolk cholesterol level in the experiment, 20 eggs (5 eggs from each replicate) were taken from each group at $4^{\text {th }}$ and $8^{\text {th }}$ weeks of experiment. The eggs were boiled for 10 minutes to ensure solidification of the egg yolk. Then the egg yolks were removed and mixed thoroughly. After homogenization, yolk samples were taken and transferred to the tubes and kept at $-80^{\circ} \mathrm{C}$ until analysis. Fat extraction from the samples was performed according to the method developed by Boselli et al. (2001). According to this method, yolk samples were added 30/70 ratio ethanol/chloroform solution at the ratio of 2:1 and stirred at $21^{\circ} \mathrm{C}$ for 30 minutes. The solution obtained at the end of the filtration was filtered through a vacuum cleaner filter. Egg cholesterol levels were determined spectrophotometrically using the Boehringer Manheim Gmbh Biochemica (1989) method with the appropriate kit.

\section{Biochemical Analyses}

At the end of the experiment, 2 birds were randomly selected per replicate from each treatment group and starved for $12 \mathrm{~h}$ before slaughter. Total 32 quails were slaughtered by severing the jugular vein and blood samples were taken and transferred to anticoagulant tubes.

To separate the serum, the tube was centrifuged at $2000 \mathrm{rpm}$ for 10 minutes. After centrifugation, serum samples were transferred to tubes and stored at $-80^{\circ} \mathrm{C}$ until analyzed. Glucose, triglyceride, cholesterol, HDL and LDL lipoprotein levels in serum were measured spectrophotometrically according to the protocols of commercial kits (Erba Mannheim, CZ). 
Table 1 Ingredient and chemical composition of the diet

\begin{tabular}{l|rl|r}
\hline \multicolumn{1}{c|}{ Ingredient } & \multicolumn{1}{c|}{ Calculated Nutrient } & Composition \\
\hline Maize & 48.55 & ME, kcal/kg & 2.900 .00 \\
Soybean meal & 33.95 & Crude protein, \% & 19.78 \\
Meat-bone meal & 3.00 & Crude fiber, \% & 2.98 \\
Vegetable oil & 5.00 & Ether extract \% & 5.05 \\
Lime stone & 7.60 & Ash \% & 10.02 \\
Di calcium phosphate & 1.20 & Dry matter \% & 91.30 \\
Salt & 0.25 & Available phosphorus, \% & 0.60 \\
Vitamin premix* & 0.10 & Calcium, \% & 3.20 \\
Mineral premix ${ }^{* *}$ & 0.10 & Methionine, $\%$ & 0.40 \\
DL-Methionine & 0.20 & Methionine \& Cysteine, \% & 0.65 \\
Lysine, $\%$ & 0.05 & Lysine, \% & 0.95 \\
\hline Total & 100.00 & &
\end{tabular}

*Vitamin premix in per kg of diet: 15,000 I.U. Vitamin A, 5,000 I.U. Vitamin D, 100 I.U. Vitamin E, 5 I.U. Vitamin K, 4 I.U. Vitamin B 10.10 I.U. Vitamin $\mathrm{B}_{2}, 5$ I.U. Vitamin $\mathrm{B}_{6}, 0.03$ I.U. Vitamin $\mathrm{B}_{12}, 50 \mathrm{mg}$ Vitamin C, $60 \mathrm{mg}$ Niacin, $18 \mathrm{mg}$ Calcium D-Pantothenic acid, $2 \mathrm{mg}$ Folic Acid, $0.25 \mathrm{mg}$ Biotin, **Mineral premix in per kg of diet: $100 \mathrm{mg}$ Manganese, $80 \mathrm{mg}$ Iron, $100 \mathrm{mg}$ Zinc, $10 \mathrm{mg}$ Copper, $0.2 \mathrm{mg}$ Cobalt, $1.5 \mathrm{mg}$ Iodine, $0.2 \mathrm{mg}$ Selenium.

Liver sample of quails were taken under aseptic conditions from quails that have been slaughtered and blood samples taken. Homogenates were prepared in the liver sample. The total antioxidant and oxidant capacity (TAS and TOS) parameters were investigated and the oxidative stress index was determined. TAS and TOS levels in liver samples were determined by spectrophotometer following the methodology of commercial kit (Rel Assay, TR). To prepare the homogenate from the liver samples, $0.4 \mathrm{~g}$ was taken from the samples in sterile environment. Homogenates were prepared by washing 2 times with PBS and then centrifuging at $4000 \mathrm{~g}$ for 5 minutes. And then lysis buffer including $1 \%$ triton X-100 (Merck), $50 \mathrm{mM}$ HEPES pH 7.2, $10 \mathrm{mM}$ EDTA, $100 \mathrm{mM} \mathrm{NaH} \mathrm{PO}_{4} \quad 2 \mathrm{H}_{2} \mathrm{O}$ and $8 \%$ protease inhibitor cocktail [aprotinin , phenylmethanesulfonylfluoride (PMSF), leupeptin, sodium fluoride (Merck, EU)] was added to homogenates. Supernatants were obtained by centrifuging of detergentinsoluble cellular proteins at $12000 \mathrm{~g}$ for 10 minutes at $4^{\circ} \mathrm{C}$. TAS and TOS analyzes were determined by using the obtained homogenate samples.

\section{Total Antioxidant Status}

TAS levels of liver homogenates were analyzed using commercial kits based on the principles described above (Assay Rel Diagnostics, Turkey). For this purpose, $800 \mu \mathrm{l}$ of Reagent 1 was taken from kit and $50 \mu \mathrm{l}$ samples were added to this. The initial measurements were made at 660 $\mathrm{nm}$ wavelength in the spectrophotometer and the results were recorded. Then, $125 \mu \mathrm{L}$ of Reagent 2 was added to these test tubes and kept at room temperature for 10 minutes and measured at absorbance values of $660 \mathrm{~nm}$. The obtained values were determined as mmol Trolox Eqiv./L (Erel, 2004).

\section{Total Oxidant Status}

TOS values in liver samples were determined according to equivalent micro molar hydrogen peroxides per liter. (Erel, 2005). TOS levels of liver homogenates were analyzed using commercial kits based on the principles described above (Assay Rel Diagnostics, Turkey). For this purpose, $1000 \mu$ l of Reagent 1 in kit was taken and $150 \mu \mathrm{l}$ sample was added to them and initial measurements were made with $530 \mathrm{~nm}$ wavelength in spectrophotometer. Subsequently, $50 \mu \mathrm{L}$ of Reagent 2 was added to these test tubes and kept at room temperature for 10 minutes and then again were measured at $600 \mathrm{~nm}$ absorbance values and recorded. The values were calculated in terms of $\mu \mathrm{mol} \mathrm{H}_{2} \mathrm{O}_{2}$ Eqiv./L.

\section{Oxidative Stress Index (OSI)}

The effects licorice root powder on the oxidative stress and antioxidant system were determined by investigating total antioxidant and oxidant capacity (TAS and TOS) parameters and determined with oxidative stress index. The oxidative stress index is equal to the percentage of total oxidant capacity to total antioxidant capacity. The TAS value obtained in the experiment as $\mathrm{mmol} / \mathrm{L}$ was converted to $\mu \mathrm{mol} / \mathrm{L}$ and the oxidative stress index was calculated according to the following formula (Kosecik et al., 2005).

$$
\text { OSI }=\frac{\text { TOS, } \mu \mathrm{mol} \mathrm{H}_{2} \mathrm{O}_{2} \text { equiv. } / \mathrm{L}}{\mathrm{TAS}, \mu \mathrm{mol} \text { Trolox equivalent } / \mathrm{L}} \times 100
$$

\section{Statistical Method}

Statistical analysis of data was performed using the SPSS 18.0 (Statistical Package for Social Sciences) program. The data were analyzed using the One-way ANOVA variance analysis method in SPSS and the Duncan test was used to determine the statistical differences between the groups. Duncan test result $\mathrm{P}<0.05$ was considered statistically significant (SPSS, 2009).

\section{Results and Discussion}

Results of final live weight, feed intake, feed conversion ratio, egg production and egg weight of quails are presented in Table 2. During the 1-8 wks., final live weight, feed intake, feed conversion ratio and egg weight were not affected by the licorice root powder supplementation $(\mathrm{P}>0.05)$. These results are in agreement with Sedghi et al. (2010a) who showed that diets supplemented with $0,2,4$ or $6 \mathrm{~g} / \mathrm{kg}$ of licorice extract were not influenced feed intake, feed conversion ratio and 
egg weight in 58-wk-old laying hens. Contrary to our study, Awadein et al. (2010) who reported that dietary supplementation of licorice at the level of 0.1 and $0.5 \%$ had significant effect on feed intake, feed conversion ratio and egg weight in Mandarah hens. They explained that feed intake and feed conversion ratio decreased and egg weight increased with dietary licorice supplementation $(\mathrm{P}<0.05)$. The different results may be due to the different species of poultry or different form of licorice used in the researches. There is a very limited number of studies have been conducted on the use of licorice root powder or extract as supplement in laying hens or quails diet. Experiment on the addition of licorice root was made mostly on broiler chickens and the findings were compared with them. Thus, in contrast to our results, Safari and Zahedi (2016) explained that 0, 0.5, 1, 1.5 and $2 \mathrm{~g} / \mathrm{kg}$ Glycyrrhiza glabra extract significantly influenced quail body weight and feed intake during both the starter (1-21 days) and grower (21-42) periods of the study $(\mathrm{P}<0.05)$, but there was not any significant effect on feed conversion ratio during the experiment $(\mathrm{P}>0.05)$. Similarly, Myandoab and Mansoub (2012) investigated the effects of licorice root extract as a medicinal plants and probiotic in quails. They obtained that feed conversion ratio decreased and feed intake and average body weight gain increased in quails fed containing 200 ppm of licorice root extract and $1 \%$ probiotic in the diet.

Table 2 The effects of licorice root on performance parameters

\begin{tabular}{|c|c|c|c|c|c|c|}
\hline \multirow{2}{*}{ Parameters } & \multicolumn{4}{|c|}{ Licorice root $(\%)$} & \multirow{2}{*}{ SEM $^{1}$} & \multirow{2}{*}{$\mathrm{P}^{2}$} \\
\hline & 0 & 0.5 & 1.0 & 1.5 & & \\
\hline Initial live weight $(\mathrm{g})$ & $370.73 \pm 4.323$ & $370.68 \pm 4.399$ & $370.52 \pm 4.347$ & $370.01 \pm 4.313$ & 2.156 & 0.999 \\
\hline Final live weight (g) & $368.68 \pm 4.037$ & $363.42 \pm 5.496$ & $362.04 \pm 4.660$ & $368.25 \pm 4.831$ & 2.378 & 0.685 \\
\hline \multicolumn{7}{|c|}{$1-4$ week period } \\
\hline Feed Intake (g/bird/day) & $41.78 \pm 0.122$ & $41.65 \pm 0.193$ & $41.65 \pm 0.308$ & $41.78 \pm 0.100$ & 0.098 & 0.625 \\
\hline Feed Conversion Ratio (g feed/g egg) & $4.04 \pm 0.091$ & $4.32 \pm 0.136$ & $4.31 \pm 0.511$ & $4.09 \pm 0.058$ & 0.055 & 0.159 \\
\hline Egg production ( $\%$ hen day & $84.74 \pm 1.656^{\mathrm{a}}$ & $77.82 \pm 1.979^{b}$ & $78.34 \pm 2.165^{\mathrm{b}}$ & $82.36 \pm 1.371^{\mathrm{ab}}$ & 0.958 & 0.026 \\
\hline Egg weight (g/bird/day) & $10.39 \pm 0.231$ & $9.74 \pm 0.258$ & $9.72 \pm 0.268$ & $10.23 \pm 0.142$ & 0.118 & 0.097 \\
\hline \multicolumn{7}{|c|}{ 4-8 weeks period } \\
\hline Feed Intake (g/bird/day) & $41.33 \pm 0.267$ & $41.92 \pm 0.273$ & $41.75 \pm 0.511$ & $41.52 \pm 0.202$ & 0.165 & 0.618 \\
\hline Feed Conversion Ratio (g feed/g egg) & $4.15 \pm 0.090$ & $4.18 \pm 0.123$ & $4.30 \pm 0.118$ & $4.15 \pm 0.068$ & 0.050 & 0.681 \\
\hline Egg production ( $\%$ hen day) & $83.33 \pm 1.847$ & $81.96 \pm 2.476$ & $80.53 \pm 2.474$ & $83.39 \pm 1.637$ & 1.055 & 0.753 \\
\hline Egg weight (g/bird/day) & $10.00 \pm 0.206$ & $10.11 \pm 0.249$ & $9.79 \pm 0.276$ & $10.04 \pm 0.166$ & 0.112 & 0.776 \\
\hline \multicolumn{7}{|c|}{ 1-8 weeks period } \\
\hline Feed Intake (g/bird/day) & $41.55 \pm 0.150$ & $41.78 \pm 0.166$ & $41.60 \pm 0.294$ & $41.65 \pm 0.113$ & 0.096 & 9.857 \\
\hline Feed Conversion Ratio (g Feed/g egg) & $4.10 \pm 0.064$ & $4.25 \pm 0.091$ & $4.31 \pm 0.085$ & $4.12 \pm 0.044$ & 0.037 & 0.134 \\
\hline Egg production ( $\%$ hen day) & $84.04 \pm 1.226^{\mathrm{a}}$ & $79.89 \pm 1.603^{b}$ & $79.43 \pm 1.629^{b}$ & $82.87 \pm 1.054^{\mathrm{ab}}$ & 0.713 & 0.057 \\
\hline Egg weight (g/bird/day) & $10.19 \pm 0.156$ & $9.93 \pm 0.179$ & $9.75 \pm 0.189$ & $10.14 \pm 0.109$ & 0.081 & 0.203 \\
\hline
\end{tabular}

${ }^{\mathrm{a}-\mathrm{b}}$ : Means within rows with different superscripts differ significantly $(\mathrm{P}<0.05)$; ${ }^{1}$ SEM: Standard error of the mean, ${ }^{2}$ Level of significance was set at $\mathrm{P}<0.05$

Egg production ratios were obtained 84.04, 79.89, 79.43 and $82.87 \%$ and egg mass value calculated as $8.62,8.01,7.84$ and 8.43 in control, $0.5,1.0$ and $1.5 \%$ licorice root powder supplemented groups, respectively. On the contrary of our study, Awadein et al. (2010) reported that egg production increased with 0.1 and $0.5 \%$ licorice addition compared with control group. The same results were obtained by Sedghi et al. (2010a) who reported that diet supplemented with $4 \mathrm{~g} / \mathrm{kg}$ of licorice extract had greater $(\mathrm{P}<0.06)$ egg production than the control fed diet during the experiment.

The effects of licorice root powder supplementation on serum parameters of laying quails are shown in Table 3. Licorice root powder supplementation did not significantly affect serum cholesterol, triglyceride and HDL concentration $(\mathrm{P}>0.05)$. However, compared to control diet, $0.5,1.0$ and $1.5 \%$ licorice root powder supplementation decreased triglyceride concentration by 1.38, 11.79 and $21.42 \%$, and increased HDL concentration by $6.37,18.81$ and $23.73 \%$, respectively. Similar results obtained by the Sedghi et al. (2010b) who explained that licorice extracts at the levels of $0.5,1.0$ and $2.0 \mathrm{~g} / \mathrm{kg}$ decreased cholesterol and triglyceride concentration and increased HDL concentration in broilers.

Sharifi et al. (2013) reported that the increase in plasma HDL levels may be due to the inhibition of the active enzyme hepatic 3-hydroxy-3-methylglutarylcoenzyme A (HMG-COA). The enzyme 3-hydroxy-3methylglutaryl-coenzyme A (HMG-CoA) reductase is the rate-limiting enzyme in cholesterol biosynthesis that catalyzes the conversion of HMG-CoA (Friesen and Rodwell, 2004). Indeed, it is suggested that medicinal plants cause a decrease in HMG-COA enzyme synthesis (Yu et al., 1998). Results of the present study for serum cholesterol and triglyceride concentration agree with AlDaraji, 2012a; Myandoab and Mansoub, 2012 and Rezaei et al., 2014. Myandoab and Mansoub (2012) who reported that the levels of serum cholesterol and triglyceride concentration reduced with licorice root supplementation in quails. In contrast to our results Salary et al. (2014) stated that the inclusion of 0.2 and $0.4 \%$ licorice extracts in drinking water of broiler did not decreased triglyceride and cholesterol level.

There was statistically significant difference in serum LDL concentration levels among the experimental groups $(\mathrm{P}<0.05)$. Licorice root powder supplementation to the 
experimental diets decreased the LDL concentration and $1.0 \%$ licorice root powder supplemented group had the lowest LDL level. Results also revealed that the addition of licorice root resulted in significant $(\mathrm{P}<0.05)$ increase in serum glucose compared with control group. This result is in agreement with findings of Al-Daraji (2012a) and Al-Daraji (2012b). Al-Daraji (2012b) investigated the effect of licorice extract supplemented diet on aflatoxin degradation and blood parameters in broiler chickens. They explained that addition of 150,300 or $450 \mathrm{mg} / \mathrm{kg}$ of licorice root extract to the diet increased plasma glucose level with increasing supplementation $(\mathrm{P}<0.05)$. In contrast to present study Myandoab and Mansoub (2012) explained that plasma glucose concentration was not significantly different among the groups. Also Sedghi et al. (2010b) stated that glucose concentration in broiler fed with $0.5, \quad 1.0$ and $2.0 \mathrm{~g} / \mathrm{kg}$ licorice extracts supplementation decreased glucose concentration. Blood glucose level is important in birds. Because glucose is utilized by birds for a variety of functions with the main use being for energy production through cellular oxidation, glycogen synthesis in liver and glycolytic muscles, fatty acid synthesis as well as synthesis of nonessential amino acids, vitamin $\mathrm{C}$, and other metabolites (Braun and Sweaze, 2008). The increase in glucose level in treatment group may be caused by the glycyrrhizin which is active component of licorice root. Glycyrrhizin is a saponin glycoside that is 60 times sweeter than cane sugar (Roshan et al., 2012).

Table 3 The effects of licorice root supplement on plasma biochemical parameters*

\begin{tabular}{l|cccccc}
\hline \multirow{2}{*}{$\begin{array}{c}\text { Parameters } \\
(\mathrm{mg} / \mathrm{dL})\end{array}$} & \multicolumn{4}{|c}{ Licorice Root Supplementation, $(\%)$} & \multirow{2}{*}{ SEM $^{1}$} & \multirow{2}{*}{$\mathrm{P}^{2}$} \\
\cline { 2 - 6 } & 0 & 0.5 & 1.0 & 1.5 & 3.179 & 0.365 \\
Cholesterol & $173.45 \pm 6.048$ & $167.73 \pm 6.717$ & $157.85 \pm 4.415$ & $166.73 \pm 8.424$ & 3.15 \\
Triglyceride & $1031.50 \pm 62.305$ & $1017.28 \pm 92.795$ & $909.85 \pm 72.148$ & $810.55 \pm 49.490$ & 37.354 & 0.121 \\
LDL & $65.36 \pm 2.861^{\mathrm{a}}$ & $52.20 \pm 6.163^{\mathrm{ab}}$ & $41.44 \pm 7.224^{\mathrm{b}}$ & $46.31 \pm 6.531^{\mathrm{b}}$ & 3.247 & 0.046 \\
HDL & $85.75 \pm 5.941$ & $91.22 \pm 8.097$ & $101.88 \pm 9.324$ & $106.10 \pm 8.135$ & 4.058 & 0.267 \\
Glucose & $217.77 \pm 9.581^{\mathrm{b}}$ & $276.43 \pm 10.265^{\mathrm{ab}}$ & $293.50 \pm 26.908^{\mathrm{a}}$ & $300.51 \pm 30.857^{\mathrm{a}}$ & 11.828 & 0.047 \\
\hline
\end{tabular}

${ }^{a-b}$ : Means within rows with different superscripts differ significantly $(\mathrm{P}<0.05) ;{ }^{1}$ SEM:Standard error of the mean, ${ }^{2}$ Level of significance was set at $\mathrm{P}<0.05$

Table 4 The effects of licorice root supplement on egg yolk cholesterol level*

\begin{tabular}{|c|c|c|c|c|c|c|}
\hline \multirow{2}{*}{ Parameters (mg/g) } & \multicolumn{4}{|c|}{ Licorice Root Supplementation, (\%) } & \multirow{2}{*}{$\mathrm{SEM}^{1}$} & \multirow{2}{*}{$\mathrm{P}^{2}$} \\
\hline & 0 & 0.5 & 1.0 & 1.5 & & \\
\hline Egg yolk cholesterol $4^{\text {th }}$ week & $17.95 \pm 0.554$ & $17.66 \pm 0.42$ & $17.40 \pm 0.208$ & $16.63 \pm 0.287$ & 0.212 & 0.139 \\
\hline Egg yolk cholesterol $8^{\text {th }}$ week & $16.96 \pm 0.496$ & $15.87 \pm 0.501$ & $15.92 \pm 0.430$ & $15.52 \pm 0.448$ & 0.249 & 0.199 \\
\hline Mean egg yolk cholesterol & $17.46 \pm 0.387$ & $16.76 \pm 0.429$ & $16.66 \pm 0.335$ & $16.27 \pm 0.266$ & 0.188 & 0.164 \\
\hline
\end{tabular}

${ }^{\mathrm{a}-\mathrm{b}}$ : Means within rows with different superscripts differ significantly $(\mathrm{P}<0.05) ;{ }^{1}$ SEM: Standard error of the mean, ${ }^{2}$ Level of significance was set at $\mathrm{P}<0.05$

Table 5 Effects of licorice root supplementation on oxidative stress and antioxidant system

\begin{tabular}{l|cccccc}
\hline \multirow{2}{*}{ Parameters } & \multicolumn{4}{|c}{ Licorice Root Supplementation, $(\%)$} & \multirow{2}{*}{ SEM $^{1}$} & \multirow{2}{*}{$\mathrm{P}^{2}$} \\
\cline { 2 - 5 } & 0 & 0.5 & 1.0 & 1.5 & \\
TAS $^{3}(\mathrm{mmol}$ Trolox equivalents/L & $0.479 \pm 0.053^{\mathrm{b}}$ & $0.460 \pm 0.054^{\mathrm{b}}$ & $0.579 \pm 0.050^{\mathrm{ab}}$ & $0.631 \pm 0.019^{\mathrm{a}}$ & 0.027 & 0.072 \\
$\mathrm{TOS}^{4}\left(\mu \mathrm{mol} \mathrm{H} \mathrm{O}_{2}\right.$ equivalents $\left./ \mathrm{L}\right)$ & $22.42 \pm 2.134^{\mathrm{a}}$ & $19.489 \pm 2.854^{\mathrm{a}}$ & $12.191 \pm 0.899^{\mathrm{b}}$ & $11.97 \pm 0.615^{\mathrm{b}}$ & 1.350 & 0.002 \\
$\mathrm{OSI}^{5}$ & $4.924 \pm 1.011^{\mathrm{a}}$ & $4.771 \pm 1.437^{\mathrm{ab}}$ & $2.222 \pm 0.136^{\mathrm{ab}}$ & $1.937 \pm 0.103^{\mathrm{b}}$ & 0.533 & 0.058 \\
\hline
\end{tabular}

${ }^{\mathrm{a}-\mathrm{b}}$ : Means within rows with different superscripts differ significantly $(\mathrm{P}<0.05) ;{ }^{1}$ SEM: Standard error of the mean, ${ }^{2}$ Level of significance was set at $\mathrm{P}<0.05$; TAS $^{3}$ : Total Antioxidant Status, TOS $^{4}$ : Total Oxidant Status, OSI ${ }^{5}$ : Oxidative Stress Index

There were no significant differences in egg yolk cholesterol among the groups (Table 4) (P>0.05). However, the egg yolk cholesterol levels decreased with increasing level of licorice root powder supplementation. At the $4^{\text {th }}$ and $8^{\text {th }}$ weeks of the experiment, control group had the highest egg yolk cholesterol content while the lowest egg yolk cholesterol level was determined in the $1.0 \%$ supplemented group. Awadein et al. (2010) used 0.1 and $0.5 \%$ licorice root as a source of phytoestrogens in the layers diets and stated that egg cholesterol levels were significantly lower in $0.1 \%$ and $0.5 \%$ licorice supplemented groups than the control group.

Results revealed that quails supplemented with the licorice root powder had a positive effect on the oxidative stress index (OSI), TAS and TOS value. Significant decreases in the TOS values obtained with increasing level of licorice root powder supplementation $(\mathrm{P}<0.05)$ (Table 5). Thus Haraguchi et al. (2000) stated that isoflavan derivatives, glabridin (1), hispaglabridin A (2), hispaglabridin B (3), 4'-Omethylglabridin (4) and 3'hydroxy-4'-O-methylglabridin (5), isolated from Glycyrrhiza glabra, were investigated for their ability to protect liver mitochondria against oxidative stresses. Mitochondrial lipid peroxidation linked to respiratory electron transport and that induced non-enzymatically were inhibited by these isoflavans. Vaya et al. (1997) analyzed the antioxidative properties of natural compounds from the root of the plant Glycyrrhiza glabra (licorice) toward LDL oxidation. They isolated seven constituents, with antioxidant capacity from Glycyrrhiza glabra. The isolated compounds were identified as the isoflavans Hispaglabridin A (1), Hispaglabridin B (4), Glabridin (3), and 4*-O-Methylglabridin (2), the two chalcones, isoprenylchalcone derivative (5) and Isoliquiritigenin (6), and the isoflavone, Formononetin (7). The antioxidative capacities of the isolated 
compounds (1-7) were tested against $\beta$-carotene destruction and LDL oxidation. They explained that supplementation of specific licorice constituents to normal human diet, may protect to a certain extent plasma LDL from oxidation.

TAS value results show that the licorice root has antioxidant effect. As a matter of fact, it was determined that the level of total antioxidant increased with increasing levels of licorice root powder supplementation. But there were no significantly differences between treatment groups $(\mathrm{P}>0.05)$. TAS value was determined as $0.479,0.460,0.579$ and $0.631 \mathrm{mmol}$ Trolox equivalents/L in the groups containing $0,0.5,1.0$ and $1.5 \%$ licorice root, respectively $(\mathrm{P}>0.05)$. Similar results were obtained by the (Visavadiya and Narasimhacharya, 2006; Sen et al., 2011; Zhao et al., 2011; Habibi et al., 2014) who found that licorice root has antioxidant capacity. Visavadiya and Narasimhacharya (2006) investigated the hypocholesterolaemic and antioxidant effects of Glycyrrhiza glabra root powder in hypercholesterolaemic male albino rats. They reported that Glycyrrhiza glabra root powder administration to hypercholesterolaemic rats decreased hepatic lipid peroxidation with a concomitant increase in superoxide dismutase (SOD) and catalase activities and total ascorbic acid content. Glycyrrhiza glabra root powder increased hepatic HMG-CoA reductase activity in rats supplemented with 5 and 10 gm\% level. Sen et al. (2011) stated that oxidative stress parameters, namely, serum superoxide dismutase, catalase, malondialdehyde in diabetic rats were reverted to respective normal values after glycyrrhizin administration.

The results of the present study suggested that the licorice root powder could be used in laying quail diets without negative effect on performance. Licorice root powder could be used in quail diets to increase antioxidant capacity and used as a feed additive to lower cholesterol levels in quail eggs.

\section{Acknowledgements}

This research was supported by the Niğde Ömer Halisdemir University the Scientific Research Projects Unit with FEB 2015/16-BAGEP project number.

\section{References}

Al-Daraji HJ. 2012a. The use of licorice extract for alleviate the adverse effects of heat stress on physiological performance of broiler chickens. International Journal of Pharmaceutical and Phytopharmacological Research, 2(2): 79-82.

Al-Daraji HJ. 2012b. Effect of liquorice extract supplemented diet on aflatoxin degradation and blood parameters in broiler chickens. International Journal of Pharmaceutical and Phytopharmacological Research, 2(2): 87-91.

Asl MN, Hosseinzadeh H. 2008. Review of pharmacological effects of Glycyrrhiza sp. and its bioactive compounds. Phytother Res., 22:709-724.

Awadein NB, Eid YZ, Abd El-Ghany FA. 2010. Effect of dietary supplementation with phytoestrogens sources before sexual maturity on productive performance of Mandarah hens. Egyptian Poultry Science, 30(3): 829-846.

Boehringer Manheim GmbH Biochemica 1989. Methods of biochemical analysis and food analysis. Manheim-Germany, 26-28.
Boselli E, Velazco V, Caboni MF, Lercker G. 2001. Pressurized liquid extraction of lipids for the determination of oxysterols in egg contained food. Journal of Chromatography A., 917: 239-244.

Doğan Y. 2004. Ratlarda Meyan Kökünün Oksidatif Antioksidatif Sistem Üzerine Etkileri. Harran Üniversitesi Sağlık Bilimleri Enstitüsü Yüksek Lisans Tezi.

Erel O. 2004. A novel automated direct measurement method for total antioxidant capacity using a new generation, more stable ABTS radicalcation. Clin. Biochem., 37:277-85.

Erel O. 2005. A new automated colorimetric method for measuring total oxidant status. Clin. Biochem., 38(12):11031111.

Friesen JA, Rodwell VW. 2004. The 3-hydroxy-3methylglutaryl coenzyme-A (HMG-CoA) reductases. Genome Biol., 5(11): 248.

Fiore C, Eisenhut M, Krausse R, Ragazzi E, Pellati D, Armanini D, Bielenberg J. 2008. Antiviral effects of glycyrrhiza species. Phytother. Res., 22: 141-148.

Fuhrman B, Volkova N, Kaplan M, Presser D, Attias J, Hayek T, Aviram M. 2002. Antiatherosclerotic effects of licorice extract supplementation on patients: Increased resistance of LDL to atherogenic modifications, reduced plasma lipid levels, and decreased systolic blood pressure. Nutr., 18(3):268-273.

Habibi R, Sadeghi GH, Karimi A. 2014. Effect of different concentrations of ginger root powder and its essential oil on growth performance, plazma metabolites and antioxidant status in broiler chicks under heat stress. British Poultry Science, 55(2):228-237.

Haraguchi H, Yoshida N, Ishikawa H, Tamura Y, Mizutani K, Kinoshita T. 2000. Protection of mitochondrial functions against oxidative stresses by isoflavans from Glycyrrhiza glabra. J Pharm Pharmacol., 52: 219-23.

$\mathrm{Ju}$ HS. 1989. Effects of Glycyrrhiza flavonoids on lipid peroxidation and active oxygen radicals. Acta Pharmaceutica Sinica, 24(11): 807-812.

Kohlert C, van Rensen I, Marz, R, Schindler G, Graefe EU, Veit M. 2000. Bioavailability and pharmacokinetics of natural volatile terpenes in animals and humans. Planta Medica, 66: 495-505.

Kosecik M, Erel O, Sevinc E, Selek S. 2005. Increased oxidative stress in children exposed to passive smoking. Int. J. Cardiol., 100: 61-64.

Myandoab MP, Mansoub NH. 2012. Comparative effect of Liquorice root extract medicinal plants and probiotic in diets on performance, carcass traits and serum composition of Japanese Quails. Global Veterinaria, 8(1):39-42.

Nakagawa K, Kishida H, Arai N, Nishiyama T, Mae T. 2004. Licorice flavonoids suppress abdominal fat accumulation and increase in blood glucose level in obese diabetic KKA(y) mice. Biol. Pharm. Bull., 27:1775-1778.

Nitalikar MM, Munde KC, Dhore BV, Shikalgar SN. 2010. Studies of Antibacterial Activities of Glycyrrhiza glabra Root Extract. Int.J. PharmTech Res., 2(1): 899-901.

NRC 1994. Nutrient Requirements of Poultry. 9th Revised Edition, National Academy Press, Washington DC.

Rezaei M, Kalantar M, Nasr J. 2014. Thymus Vulgaris L., Glycyrrhiza Glabra, and Combo Enzyme in Corn or BarleyBasal Diets in Broiler Chickens. International Journal of Plant, Animal and Environmental Sciences, 4(3): 418-423.

Safari A, Zahedi A. 2016. The effect of different levels supplementation of Glycyrrhiza glabra extract on growth performance in male quail. International Journal of Advanced Biological and Biomedical Research, 4(2):214219.

Salary J, Kalantar M, Sahebi ala MK. Ranjbar K, Hemati Matin HR. 2014. Drinking water supplementation of licorice and aloe vera extracts in broiler chickens. Scientific Journal of Animal Science, 3(2): 41-48. 
Sedghi M, Golian AGH, Soleymani P. 2010a. Effect of Dietary Supplementation of Licorice Extract on Egg Quality and Performance of Hens. Veterinary Clininal Pathology, 4(15):933-941.

Sedghi M, Golian A, Kermanshahi H, Ahmadi H. 2010b. Effect of dietary supplementation of licorice extract and a prebiotic on performance and blood metabolites of broilers. South African Journal of Animal Science, 40(4):371-380.

Sen S, Royt M, Chakraborti AS. 2011. Ameliorative effects of glycyrrhizin on streptozotocin-induced diabetes in rats. Journal of Pharmacy and Pharmacology, 63:287-296.

Sharifi SD, Saeedeh H, Khorsandi A, Khadem A, Salehi A, Moslehi HR. 2013. The effect of four medicinal plants on the performance, blood biochemical traits and ileal microflora of broiler chicks. Veterinarski arhiv, 83(1):69-80.

Shibata S. 2000. A drug over the millennia: Pharmacognosy, chemistry and pharmacology of licorice. J. Pharm. Soc. Jpn., 120: 849-862.

SPSS Inc. Released 2009. PASW Statistics for Windows, Version 18.0. Chicago: SPSS Inc.

Tan G, Zhu Z, Zhang H, Zhao L, Liu Y, Dong X, Lou Z, Zhang G, Chai Y. 2010. Analysis of phenolic and triterpenoid compounds in licorice and rat plasma by high-performance liquid chromatography diode-array detection, time-of-flight mass spectrometry and quadrupole ion trap mass spectrometry. Rapid Communications in Mass Spectrometry, 24: 209-218.
Vaya J, Belinky PA, Aviram M. 1997. Antioxidant constituents from licorice roots isolation, structure elucidation and antioxidative capacity toward LDL oxidation. Free Radical Bio. Med. 23:302-313.

Visavadiya NP, Narasimhacharya AVRL. 2006. Hypocholesterolaemic and antioxidant effects of Glycyrrhiza glabra (Linn) in rats. Mol. Nutr. Food Res., 50:1080-1086.

Yokota T. Nishio H. Kubota Y. Mizoguchi M. 1998. The inhibitory effect of glabridin from licorice extracts on melanogenesis and inflammation. Pigment Cell Res., 11:355-361.

Yu SG, Hsu JC, Chiou PWS. 1998. Effects of $\beta$-glucanase supplementation of barley diets on growth performance of broilers. Animal Feed Science and Technology, 70:353-361.

Zhang Q, Ye M. 2009. Chemical analysis of the Chinese herbal medicine Gan-Cao (licorice). J Chromatogr A., 1216(11):1954-1969.

Zhao X, Yang B, Yang WR, Wang Y, Jiang SZ, Zhang, GG. 2011. Effects of ginger root (Zingiber officinale) on laying performance and antioxidant status of laying hens and on dietary oxidation stability. Poultry Science, 90:1720-1727. 